\title{
论 文
}

\section{豹属线粒体基因组分析}

\author{
魏砳 ${ }^{(1)}$ ，吴孝兵 ${ }^{(1 *}$, 诸立新 ${ }^{(1)}$ (3)，蒋志刚 ${ }^{(4)}$ \\ (1) 安徽师范大学生命科学学院重要生物资源保护与利用安徽省重点实验室, 芜湖 241000; \\ (2) 宿州职业技术学院, 宿州 234000; \\ (3) 滁州学院化学与生命科学系, 滁州 239000; \\ (4) 中国科学院动物研究所动物生态与保护生物学实验室, 北京 100080 \\ * 联系人, E-mail: wuxb@mail.ahnu.edu.cn
}

收稿日期: 2011-01-05; 接受日期: 2011-06-10

国家自然科学基金(批准号：30470244 和 30870359)、安徽省优秀青年基金(批准号：04043409)、安徽省教育厅自然科学基金(批准号: KJ2009B015)和重要生物资源保护与利用安徽省重点实验室资助项目

\begin{abstract}
摘要采用 PCR 扩增方法, 测定了虎、豹和雪豹线粒体基因组全序列，长度分别为 16990, 16964 和 $16773 \mathrm{bp}$. 每个线粒体基因组包括: 13 个蛋白编码基因, 22 个 tRNA, 2 个 rRNA，一个 非编码的控制区(D-loop) 以及一个轻链复制起点 $\left(\mathrm{O}_{\mathrm{L}} \mathrm{R}\right)$ ，其基因组结构与家猫、美洲狮和云豹 具有较高的相似性. 基于两组线粒体合并序列和线粒体全序列，采用最大简约法、最大似然 法及贝叶斯法(Bayesian)推测豹属的分子系统关系. 结果显示, 豹属(Panthera) 成、豹、雪豹、 美洲虎、狮和云豹组成，云豹并归于豹属. 属内物种间的系统关系为: 云豹(虎(美洲虎(豹(狮, 雪豹)) )). 基于 ML 最优树的枝长和 4 个可靠的分歧时间校正点进行了分歧时间的估算, 豹属 约在 11.3 百万年前(MYA)从猫科动物中分化出来; 云豹、虎、雪豹和豹的分化时间分别为 8.66, 6.55, 4.63 和 4.35 MYA, 比化石时间略早. 尤其是雪豹这一青藏高原的特有物种, 其分歧事 件、演化过程、物种形成和分布模式与发生在 8, 3.6, 2.5 和 1.7 MYA 晚新生代青藏高原的 地质构造事件及气候重大转型期呈现相关性.
\end{abstract}

关键词
雪豹
豹
虎

线粒体全序列

系统发育

分歧时间
现存的猫科动物起源于晚新生代, 是世界上进 化最为成功的食肉动物, 除南极洲外, 猫科动物广泛 分布于亚洲、非洲、欧洲、北美洲和南美洲 ${ }^{[1]}$. 化石和 分子证据显示, 猫科动物大约在 10 百万年前(MYA) 15 MYA 从共同的祖先快速演化而来, 与无数现存的 物种一样, 其独特的辐射演化使其在生态、形态和行 为习性上展示出不同的特性 ${ }^{[2-5]}$. 快速和最近的物种 形成, 较少区别的牙齿和骨骼特征, 平行进化事件以 及不完全的化石记录使豹属物种演化历史与分歧时 间的研究变得非常复杂 ${ }^{[1]}$.
早期的研究包括全部形态结构, 比较形态学、比 较细胞学、蛋白免疫距离、DNA 杂交、异型酶电泳、 逆转录病毒的遗传、性染色体基因和化学信号 ${ }^{[6 ~ 14]}$. 最近的研究主要集中在线粒体基因, 利用线粒体基 因序列来探讨猫科动物的系统进化关系 ${ }^{[15]}$. 因为线 粒体基因组在基因结构、基因排列方式和表达模式等 方面均显示了极大的多样性, 这种多样性可能反映 了真核细胞不同的进化路线 ${ }^{[16]}$. 目前, 线粒体基因是 一个能够从基因组水平上来分析动物系统发生的分 子标记, 可以从线粒体基因组序列信息、基因组成及 
基因排列方式等进行多方位的分子进化研究, 因而 线粒体基因组全序列成为研究动物分子系统发生最 有力的证据之一 ${ }^{[17]}$.

豹属作为最近进化而来的一个类群, 其物种的 分类地位及进化关系一直存在争议 ${ }^{[11,18]}$. 迄今, GenBank 数据库中收录 3 种猫科动物的线粒体全序

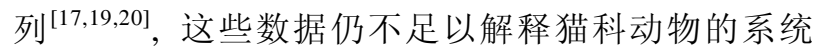
发生关系. 本研究中, 测定了虎(Panthera tigris)、豹 (Panthera pardus)和雪豹(Panthera uncia)线粒体基 因组全序列, 并与家猫(Felis catus)、猎豹(Acinonyx jubatus)和云豹(Neofelis nebulosa) 的线粒体基因组全 序列进行比对, 探讨豹属线粒体基因组全序列的结 构及进化等特点. 本文使用线粒体基因合并序列和 全序列来进行系统分析, 试图更好地理解它们的系 统关系.

\section{1 材料与方法}

\section{1 样品来源与 DNA 提取和扩增}

虎、豹的肌肉样品和雪豹的毛皮样品来自安徽省 宁国标本厂. 样品 $-80^{\circ} \mathrm{C}$ 保存于安徽师范大学生命科 学学院重要生物资源保护与利用安徽省重点实验室.

用线粒体萃取试剂盒(GENMED Scientifics Inc., USA)抽提与萃取线粒体 DNA, 包括两个步骤: 在冰 上操作, 用线粒体分离试剂盒进行粗提线粒体细胞 器; 在 $4^{\circ} \mathrm{C}$ 条件下, 用线粒体 DNA 萃取试剂盒萃取线 粒体 DNA. 电泳检测 mtDNA 样品与总 DNA, 排除总 DNA 的干扰. 根据 GenBank 已公布的家猫、猎豹和 云豹线粒体基因组全序列及虎的部分线粒体基因组 序列, 利用 Oligo 6.0 软件设计出 34 对引物(表 1) ${ }^{[21]}$. PCR 反应都在 PTC-200 型 DNA 扩增仪上进行. 反应 总体系为 $30 \mu \mathrm{L}$, 其中含有 $10 \mathrm{mmol}$ Tris- $\mathrm{HCl}(\mathrm{pH} 8.3)$, $50 \mathrm{mmol} \mathrm{KCl}, 1.5 \mathrm{mmol} \mathrm{MgCl}_{2}, 100 \mu \mathrm{mol}$ dNTPs, 引 物各 $0.25 \mu \mathrm{mol}, 1 \mathrm{U} \mathrm{Taq}$ DNA 聚合酶, 总 DNA 约 25 ng. 反应程序为: $94^{\circ} \mathrm{C}$ 变性 $45 \mathrm{~s}, 52 \sim 60^{\circ} \mathrm{C}$ 复性 $50 \mathrm{~s}$, $72^{\circ} \mathrm{C}$ 延伸 $50 \mathrm{~s}$, 共进行 32 个循环. 循环前 $95^{\circ} \mathrm{C}$ 预变 性 $5 \mathrm{~min}$, 循环后继续延伸 $7 \mathrm{~min}$. 扩增得到的 PCR 产物于 $1 \%$ 琼脂糖电泳检测.

\subsection{DNA 序列分析}

扩增产物用胶纯化试剂盒(杭州爱思进生物技术
有限公司)纯化, 纯化产物在全自动遗传分析仪上测 序. 用软件 DNASTA ${ }^{[22]}$ 和 ClustalX $\mathrm{X}^{[23]}$ 对序列进行对 比和拼接, 用 SEQUIN(Version 5.35)软件查找确定了 13 个蛋白质编码基因, 并预测氨基酸序列; 2 个 rRNA 基因的位置通过与其他猫科动物的序列比对 来确定; 用 tRNAscan-SE1.21(http://lowelab.ucsc.edu/ tRNAscan-SE) 定位 tRNA 基因, 并用 DNAsis(Version 2.5, Hitachi Software Engineering)模拟 tRNA 的二 级结构. 最终获得了豹、虎和雪豹的线粒体全序列 并提交 GenBank(登录号: EF551002, EF551003 和 EF551004).

\section{3 分子系统分析}

为探讨豹属起源和分化以及进一步阐明豹属各 物种间的系统发生关系, 从 GenBank 数据库中分别 下载云豹、猎豹和家猫的线粒体全序列以及狮 (Panthera leo)、美洲豹(Panthera onca)、美洲狮(Puma concolor)和猞猁(Lynx lynx)的 7 个线粒体基因(表 2). 根 据以下 3 种方式, 以犬作为外群, 分别构建系统树: 组合 I : 5 个线粒体蛋白质编码基因合并序列(ND2+ $N D 4+N D 5+A T P 8+C y t b)$; 组合 II : 7 个线粒体基因合并 序 列 $(12 \mathrm{SrRNA}+16 \mathrm{SrRNA}+N D 2+N D 4+N D 5+A T P 8+$ $C y t b)$; 基因组全序列. 对于合并序列, 采用 $\chi^{2}$ 检验序 列间碱基组成的均质性; 核苷酸替代饱和性分析通 过绝对颠换 $(\mathrm{Tv})$ 和转换 $(\mathrm{Ti})$ 数与序列分支关系图来检 验; 在使用部分或全部编码区进行数据分析时, 删除 第三密码子转换, 去除饱和效应的影响.

系统发育分别采用最大简约法、最大似然法和贝 叶斯法进行分析. MP, ML 分析在 PAUP* 4.0b10 ${ }^{[24]}$ 中 完成, 参数设置如下: 选择启发式搜索 (heuristic search)、树二等分再连接选项(tree-bisection reconnection, TBR)和 100 次随机加入序列(addition sequence replicates)等参数进行搜索最大简约树和最大似然树. 所有位点均作无序特征处理, 分析前排除所有无信息 位点. 检验 MP, ML 树中各节点可信度采用非参数自展 法(non-parametric bootstrap)重复检测, 用自展值(1000 replicates) 来检验各节点的支持率, 置信度 (bootstrap values) $>70 \%$ 为有意义支持, 置信度(bootstrap values) 在 $50 \% \sim 70 \%$ 为无效支持 ${ }^{[25]}$, 参数设定: nreps $=1000$, search=heuristic, conlevel $=50$, addseq $=$ random, swap $=$ TBR. 
表 1 豹、虎和雪豹线粒体全序列测定所用引物 a)

\begin{tabular}{|c|c|c|c|}
\hline 引物编号 & 上游引物序列 $\left(5^{\prime} \rightarrow 3^{\prime}\right)$ & 下游引物序列 $\left(5^{\prime} \rightarrow 3^{\prime}\right)$ & 退火温度 $\left({ }^{\circ} \mathrm{C}\right)$ \\
\hline F1-U/D & TGAAAATGCCTAGATGAG & ATCTTCTGGGTGTAAGCC & 54.0 \\
\hline F2-U/D & AATATGTACAYACCGCCCGTC & ATTACGCTACCTTYGCACG & 54.5 \\
\hline F3-U/D & AACTCGGCAAACACAAGCC & TCGTTCAACTAGGGTTAGG & 55.0 \\
\hline F4-U/D & TCAGAGGTTCAATTCCTC & TAGGATTAGGTTCGATTCC & 54.0 \\
\hline F5-U/D & CAAGYATCCCACCTCAAAC & CAGCCTATATGGGCGATTG & 55.0 \\
\hline F6-U/D & ССТАСТССТАACAATATCC & AGCAGTCCCTACTATACC & 56.0 \\
\hline F7-U/D & CAGTCTAATGCTTACTCAGC & AGTATGCTCGTGTGTCTAC & 55.0 \\
\hline F8-U/D & ATCGTCACCTACTACTCC & GTGGTCGTGRAAGTGTAG & 55.0 \\
\hline F9-U/D & TGGTTTCAAGCCAATGCC & GATGTATCTAGTTGTGGC & 54.0 \\
\hline F10-U/D & GTTCTTGAATTAGTYCCCC & GTTATAAGGAGGGCTGAAAG & 53.0 \\
\hline F11-U/D & TGCTGTAGCCCTAATCCAA & TGTCTGTTTGTGAGGCTC & 56.0 \\
\hline F12-U/D & TATGAGTGCGGATTTGACCC & CGTTCCGTTTGATTACCTC & 53.0 \\
\hline F13-U/D & TCTAGTAGGCTCACTACC & GGTTCCTAAGACCAATGGA & 52.0 \\
\hline F14-U/D & GAACTGCTAATTCATGCCTC & GTAGAAAYGCGAGGTAAG & 53.0 \\
\hline F15-U/D & GCTATCTGTGCTCTCACAC & ARTAAGAGTARGCTGAGGG & 54.0 \\
\hline F16-U/D & TGAGCCAAAARTCCGCATC & GTGCCAAAGTTTCATCAYG & 53.5 \\
\hline F17-U/D & CCCTCAGAATGATATTTGTCCTCA & TGAGATCTGAAAAACCATCGTTG & 53.0 \\
\hline F18-U/D & GCTCCTACACCTTCTCAG & GCACAGTATGGGTATATG & 56.0 \\
\hline F19-U/D & TCAAGGAAGAAGCAACAGCC & GGTCATAGCTGAGTCATAGC & 52.0 \\
\hline F20-U/D & ACTGTGGTGTCATGCATTTGG & GACTCATCTAGGCATTTTCAG & 55.0 \\
\hline F21-U/D & GTCTCTCATTCTATTTATCGGGTC & GGGAATAATGCCTGTTGGT & 53.0 \\
\hline F22-U/D & CGAGACATTATCCGAGAAA & TTCAGTTCACTCTAGTCCTT & 52.0 \\
\hline F23-U/D & CACGAGAAAACGCCTAAT & GACCCAGAGCACATCAATAA & 53.0 \\
\hline F24-U/D & ACCACCAGCCACAATCAAA & TGGATCGGAGGATTGCGTAT & 52.0 \\
\hline F25-U/D & TCCAGGTCGGTTTCTATCTA & TAGGATGGGTGCTGTGATGAAT & 53.1 \\
\hline F26-U/D & CTCTAAGTAAGCCCTATA & GCATGGGCAGTAACTACTA & 55.0 \\
\hline F27-U/D & ACACCTATTCTGATTCTTCG & GAGAATTAAGATGATGGCTGGT & 54.0 \\
\hline F28-U/D & TCAAGCCAATACCATAACCACT & TCCTATTATTGTTGGGGTA & 53.0 \\
\hline F29-U/D & ACATGCCACAGTTAGATAC & TTTGAGTGATAGAAGGCCCAGA & 53.0 \\
\hline F30-U/D & CCACTGCCATACTCATACCAAT & GTCTTTTGGTAGTCACAGGT & 54.0 \\
\hline F31-U/D & ATAACACTTCATCTGCTCCСACT & TGTTAATGCGAGGCTTCCGATA & 52.0 \\
\hline F32-U/D & TCCAGGCCCACCATAAATAG & CGTCCTACGTGCATGTATAGA & 52.0 \\
\hline F33-U/D & CACGAGAAAACACCCTAA & GCGAGACTTCCGATGATGAG & 52.0 \\
\hline F34-U/D & TCGCATTCTGATTACCCCAA & CTCTTTTGATTAGGTGTGACTG & 55.0 \\
\hline
\end{tabular}

a) $Y=C$ 或 $T, R=A$ 或 $G, K=G$ 或 $T, M=A$ 或 $C$

表 2 本研究用于系统发育分析的线粒体基因序列

\begin{tabular}{cccccccc}
\hline 物种名 & 12S rRNA & 16S rRNA & ND2 & ND4 & ND5 & Cyt $b$ & ATP8 \\
\hline Panthera uncia & EF551004 & EF551004 & EF551004 & EF551004 & EF551004 & EF551004 & EF551004 \\
Panthera pardus & EF551002 & EF551002 & EF551002 & EF551002 & EF551002 & EF551002 & EF551002 \\
Panthera tigris & EF551003 & EF551003 & EF551003 & EF551003 & EF551003 & EF551003 & EF551003 \\
Panthera onca & AY012151 & AF006441 & AY634391 & AY634403 & AF006442 & EF437582 & DQ899924 \\
Panthera leo & S9300 & AF006457 & AY170043 & AY634398 & AF006458 & S79302 & DQ899945 \\
Neofelis nebulosa & DQ257669 & DQ257669 & DQ257669 & DQ257669 & DQ257669 & DQ257669 & DQ257669 \\
Acinonyx jubatus & AY463959 & AY463959 & AY463959 & AY463959 & AY463959 & AY463959 & AY463959 \\
Puma concolor & U33495 & AF006455 & AY634392 & AY634404 & AF006456 & AY598487 & AY598483 \\
Lynx lynx & D28891 & AF006413 & AY634389 & AY634401 & AF006414 & AY773083 & AY598471 \\
Felis catus & NC_001700 & NC_001700 & NC_001700 & NC_001700 & NC_001700 & NC_001700 & NC_001700 \\
Canis familiaris & U96639 & U96639 & U96639 & U96639 & U96639 & U96639 & U96639 \\
\hline
\end{tabular}


贝叶斯分析采用 Mrbayes 3.0b4 软件 ${ }^{[26]}$. 用 MODELTEST v. 3.6 $6^{[27]}$ 软件中等级似然率(hLRT) 和 AIC (Akaike information criterion)检验标准，模拟出核苷酸 替代的最适模型为 $\mathrm{GTR}+\mathrm{I}+\mathrm{G}(\mathrm{a}$ general-time-reversible+ gamma+invariant; GTR+I+G, G=1.8671, I=0.5549). 以随机树起始, 马尔科夫链的蒙特卡洛方法(Markov chain Monte Carlo process) 设置为 4 条链同时运行 $4 \times 10^{6}$ 代(generations), 3 条热链、 1 条冷链. 每 100 代 取样并保存树一次, 最终得到 40000 棵系统发育树, 重复一次以确保 MCMC 的收玫, 将运行过程中所得 的冷链对数似然值 (log-likelihood scores) 与相应的代 数进行作图, 找到对数似然值达到饱和的位置, 到达 饱和前的数据被作为老化样本(burnin samples)舍弃. 在舍弃老化样本后, 根据剩余的样本构建一致树 (consensus tree) 并计算相关参数. 贝叶斯树(Bayesian tree)每个节点的支持率由该节点在这些取样树中出现 的百分率表示, 是该节点的后验概率 (posterior probabilities)的近似值 ${ }^{[28]}$, 以近似值(probabilities) $>95 \%$ 为有效支持 ${ }^{[29]}$.

\section{4 系统发育树检测}

采用 PAUP*4.0b10 软件中的 Shimodaira-Hasegawa(SH) 对系统发育树进行检测 ${ }^{[30]}$, 以判断不同构 树方法所构建的系统发育树之间是否收玫, 并从一 系列相互竞争的拓扑树或系统发育假设中选择最优 的系统发育树. 所有统计检验都基于同一核苷酸替 代模型, 即 GTR+G+I 模型(根据等级似然率和 AIC 选 择标准选择最适合的替代模型).

\section{5 分歧时间}

NADH6 基因是唯一编码在轻链上的基因, 因此 在核苷酸和氨基酸的组成上不同于其他线粒体蛋白 编码基因, 并且具有明显的突变偏倚. 这些因素影响

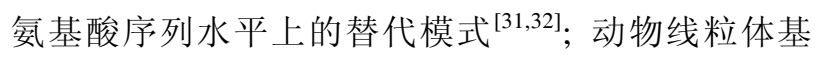
因的控制区常常有较快碱基替代和删除, 变异程度 较大 ${ }^{[33]}$, 因而在分歧时间的分析中 ND6 基因和控制 区被排除. 另外，可靠的分歧时间校正点 (calibration point) 是正确和精确估计分歧时间的一个非常重要 的因素, 它提供了重建系统树的时标(time scale) ${ }^{[34]}$.

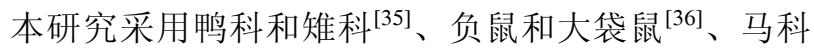
和犀科、猫科和犬科 ${ }^{[37]} 4$ 个可靠分歧时间校正点来推 算分歧时间. 4 个校正点的分歧时间与它们的化石记
录相吻合.

为了检验分子钟假设, 将有分子钟约束的 ML 树与不受分子钟约束的 ML 树的似然对数值进行比 较 ${ }^{[38]}$. 如果两者差异显著, 则分子钟被拒绝. 对数似 然比检验表明, 删除 ND6 基因和控制区数据 $\left(\chi^{2}=\right.$ $1443.035, \mathrm{~d} f=28, P<0.001)$ 序列的分子钟假设被拒绝, 不宜采用全局分子钟(global clock)来估算分支时间.

因此, 本研究采用 Janke 和 Arnason ${ }^{[39]}$ 的方法, 基于 21 个去除 ND6 基因和控制区序列的脊椎动物线 粒体序列所构建的 ML 树的枝长来估算分支之间的 分歧时间. 这种方法放宽了对严格分子钟中系统发 育类群间相同的、稳定的替代速率的约束, 而允许数 个分子钟及分化时间校正, 并且所得结果用 MEGA3. $1^{[40]}$ 软件进行了计算和验证. 本研究用于分 歧时间分析的线粒体基因组序列见表 3.

\section{2 结果}

\section{1 线粒体合并序列的特征}

组合 I 和 II 的碱基组成表现出 AT 偏倚分别为 $60.1 \%$ 和 $59.5 \%$; 低 $\mathrm{G}$ 含量, 分别为 $11.7 \%$ 和 $13.8 \%$. 特别是在密码子的第 2 和 3 位更为明显, 表现为显著

\section{表 3 本研究用于分歧时间分析的线粒体基因组序列}

\begin{tabular}{lcc}
\hline \multicolumn{1}{c}{ 物种名 } & GenBank 登录号 & 来源 \\
\hline Panthera uncia & EF551004 & 本研究 \\
Panthera pardus & EF551002 & 本研究 \\
Panthera tigris & EF551003 & 本研究 \\
Neofelis nebulosa & DQ257669 & {$[17]$} \\
Felis catus & NC001700 & {$[19]$} \\
Acinonyx jubatus & AY463959 & {$[20]$} \\
Acinonyx jubatus & AF344830 & {$[20]$} \\
Macropus robustusm & Y10524 & {$[39]$} \\
Equus asinus & X97337 & {$[41]$} \\
Canis familiaris & $\mathrm{U} 96639$ & {$[42]$} \\
Ursus maritimus & AJ428577 & {$[43]$} \\
Equus caballus & $\mathrm{X} 79547$ & {$[44]$} \\
Ceratotherium simum & $\mathrm{Y} 07726$ & {$[45]$} \\
Rhinoceros unicornis & $\mathrm{X} 97336$ & {$[46]$} \\
Didelphis virginiana & $\mathrm{Z} 29573$ & {$[47]$} \\
Gallus gallus & $\mathrm{X} 52392$ & {$[48]$} \\
Aythya americana & AF090337 & {$[49]$} \\
Rhea americana & AF090339 & {$[50]$} \\
Struthio camelus & Y12025 & {$[51]$} \\
Alligator mississippiensis & Y13113 & {$[52]$} \\
Alligator sinensis & AF511507 & {$[53]$} \\
\hline
\end{tabular}


的低 $\mathrm{G}$ 组成, 而密码子第 1 位碱基组成较为均等. 组 合 I 与 II 的比对位点分别为 3300 和 $4538 \mathrm{bp}$, 其中可 变位点分别为 1205 和 1360 , 平均可变位点分别占比 对位点的 $36.52 \%$ 和 $29.97 \%$; 简约信息位点分别为 793 和 857 , 平均可变位点分别占比对位点的 $24.03 \%$ 和 $18.88 \%$; 转换/颠换分别为 5.66 和 5.08 ; 内群的配对 距离分别为 $6.8 \%$ 16.5\%(平均 12.04)和 5.8\% 13.0\% (平均 9.06\%); 两个合并序列相比, 蛋白编码基因 合并序列显示较高的变异速率. 合并序列的特征见 表 4.

\section{2 豹、虎和雪豹 mtDNA 结构}

豹、虎和雪豹的线粒体基因组全长分别为 16964 , 16990 和 $16773 \mathrm{bp}$, 每个线粒体基因组包括 13 个蛋白 编码基因, 22 个 tRNA 基因, 2 个 rRNA 基因, 1 个控制 区和一个轻链复制起点 $\left(\mathrm{O}_{\mathrm{L}} R\right)$. 其中主链 (majoritystrand), 即 $\mathrm{H}$-链编码了 28 个基因, 而次链(minoritystrand), L-链包含了 9 个基因. 与家猫、猎豹和云豹的 基因组成及顺序相同(图 1 和表 5). 3 个物种碱基的组 成表现为 $\mathrm{A}, \mathrm{T}$ 丰富, 碱基含量的大小排列为 $A>T>C>G, A+T$ 含量比 $G+C$ 含量高, 而且 $A T$ 偏斜也 较 $\mathrm{GC}$ 高. 3 物种线粒体基因碱基组成为虎: A: $31.9 \%$; T: $26.9 \%$; C: $26.6 \%$; G: $14.6 \%$; 豹: A: $31.8 \%$; T: $27.4 \%$; C: $26.6 \%$; G: $14.5 \%$; 雪豹: A: $31.9 \%$; T: $27.1 \%$; : 26.5\%; G: $14.5 \%$.

\section{3 蛋白编码基因}

豹、虎和雪豹线粒体基因组中共包含 13 个蛋白 质编码基因, 全长 11406,11417 和 $11409 \mathrm{bp}$, 分别占 线粒体全序列的 $67.72 \%, 67.23 \%$ 和 $68.02 \%$. 在 13

\section{表 4 线粒体基因合并序列特征 ${ }^{\text {a) }}$}

\begin{tabular}{ccc}
\hline & 组合序列 I & 组合序列 II \\
\hline 比对位点(bp) & 3300 & 4538 \\
A\% & 33.0 & 33.6 \\
C\% & 28.2 & 26.8 \\
G\% & 11.7 & 13.8 \\
T\% & 27.1 & 25.9 \\
保守位点 & $2095(63.48 \%)$ & $3178(81.93 \%)$ \\
可变位点 & $1205(36.52 \%)$ & $1360(29.97 \%)$ \\
简约信息位点 & $793(24.03 \%)$ & $857(18.88 \%)$ \\
转换/颠换 & 5.66 & 5.08 \\
内群配对距离(\%) & $12.04(6.8 \sim 16.5)$ & $9.06(5.8 \sim 13.0)$ \\
\hline
\end{tabular}

a) 组合序列 I : ND2+ATP8+ND4+ND5+Cyt $b$; 组合序列 II : $12 \mathrm{~S}$ rRNA+16S rRNA+ND2+ATP $8+N D 4+N D 5+C y t b$

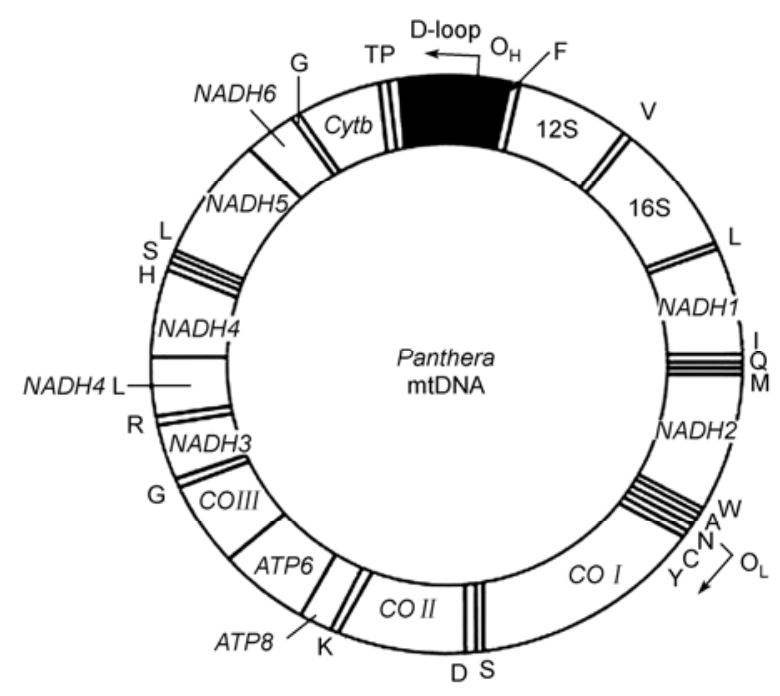

图 1 虎、豹和雪豹线粒体基因组基因构成 外环示重链编码的基因, 内环示轻链编码的基因. 12S: 12S rRNA; 16S: 16S rRNA; NADH1 NADH6: NADH 脱氢酶亚基; CO I COIII: 细胞色素氧化酶亚基 I 细胞色素氧化酶亚基III; ATP6 和 ATP8: 腺 苷三磷酸酶亚基 6 和腺苷三磷酸酶亚基 $8 ; C y t b$ : 细胞色素 $b$. 单个 字母示 $t R N A$ 基因所转运的氨基酸. $\mathrm{O}_{\mathrm{H}}$ 和 $\mathrm{O}_{\mathrm{L}}$ 分别表示重链和轻链复 制的起始区

个蛋白质编码基因中, 最长的为 $N D 5$, 最短的为 $A T P 8$, 除 ND6 基因由 $\mathrm{L}$ 链编码外, 其余均由 $\mathrm{H}$ 链编 码, 没有发现内含子, 有些基因与其他基因存在少许 重叠. 在起始密码子的使用上, 虎、豹、雪豹 3 物种 间线粒体基因组的 13 个蛋白质编码基因中, ND2 基 因以 ATC 为起始密码子, $N D 3, N D 5$ 以 ATA 为起始密 码子, 唯一变化是雪豹 $C O I I I$ 基因也是以 ATA 为起 始密码子, 其余蛋白质编码基因都是以 ATG 为起始密 码子; 在终止密码子的使用上, 3 物种的 CO I, CO II, $A T P 8, A T P 6, N D 4 L, N D 5$ 和 ND6 以 TAA 为终止密码 子, $C y t b$ 基因以 $\mathrm{AGA}$ 为终止密码子, $N D 3$ 基因以 $\mathrm{TA}$ 为终止密码子, $C O I I I, N D 2$ 和 $N D 4$ 基因以 $\mathrm{T}$ 为终止密 码子. 而其他的基因却出现如下变化: 虎和雪豹的 $N D 1$ 基因以 $\mathrm{TAA}$ 为终止密码子, 而豹的 $N D 1$ 是以 AGA 为终止密码子; 虎和豹的 COIII, ND4 基因以单 碱基 $\mathrm{T}$ 为终止密码子, 而雪豹的 COIII, ND4 基因却是 以 TAA 为终止密码子(表 5).

豹、虎和雪豹线粒体基因组 13 个蛋白编码基因 的密码子使用情况见表 6 和 7. 在蛋白编码基因中, 碱基 $\mathrm{A}$ 出现的频率最高, 其次是 $\mathrm{T}$ 或 $\mathrm{C}$. 碱基 $\mathrm{G}$ 在其 他密码子第 3 位上都是最少的, 这种低 $\mathrm{G}$ 偏倚现象在 脊椎动物中很普遍. 在豹、虎和雪豹线粒体蛋白编码 
基因中, $\mathrm{A}$ 的含量最高, 平均分别为虎 30.9\%, 豹 $31.5 \%$, 雪豹 $28.7 \%, \mathrm{G}$ 的含量最低, 平均分别为虎 $13.3 \%$, 豹 11.4\%, 雪豹 14.0\%; 蛋白质编码基因密码
子的第一、二和三位点的 $\mathrm{A}+\mathrm{T}$ 平均百分含量均高于 $\mathrm{G}+\mathrm{C}$ 含量, 其中第二位点所占比例最高. 这一点与线 粒体基因组有高 AT 偏向性的特征相吻合.

\section{表 5 虎、豹和雪豹线粒体基因组结构}

\begin{tabular}{|c|c|c|c|c|c|c|}
\hline \multirow{2}{*}{ 基因/区域 } & \multicolumn{3}{|c|}{ 位置 } & \multirow{2}{*}{ 起始密码子 } & \multirow{2}{*}{ 终止密码子 } & \multirow{2}{*}{ 轻/重链 } \\
\hline & P. tigris & P. pardus & P. uncia & & & \\
\hline D-loop & $1 \sim 927$ & $1 \sim 954$ & $1 \sim 743$ & & & $\mathrm{H}$ \\
\hline $\mathrm{tRNA}^{\mathrm{Phe}}$ & $928 \sim 998$ & $955 \sim 1025$ & $744 \sim 813$ & & & $\mathrm{H}$ \\
\hline $12 \mathrm{~S}$ rRNA & $999 \sim 1958$ & $1026 \sim 1984$ & $814 \sim 1773$ & & & $\mathrm{H}$ \\
\hline tRNA ${ }^{\text {Val }}$ & $1959 \sim 2026$ & $1985 \sim 2052$ & $1774 \sim 1841$ & & & $\mathrm{H}$ \\
\hline $16 \mathrm{~S}$ rRNA & $2027 \sim 3601$ & $2053 \sim 3624$ & $1842 \sim 3421$ & & & $\mathrm{H}$ \\
\hline $\mathrm{tRNA}^{\mathrm{Leu}(\mathrm{UUR})}$ & $3602 \sim 3676$ & $3625 \sim 3701$ & $3422 \sim 3496$ & & & $\mathrm{H}$ \\
\hline$N D 1$ & $3679 \sim 4635$ & $3704 \sim 4660$ & $3499 \sim 4455$ & ATG & AGA/TAA & $\mathrm{H}$ \\
\hline tRNA $^{\text {Ile }}$ & $4635 \sim 4703$ & $4660 \sim 4728$ & $4455 \sim 4523$ & & & $\mathrm{H}$ \\
\hline $\mathrm{tRNA}^{\mathrm{Gln}}$ & $4701 \sim 4774$ & $4726 \sim 4799$ & $4521 \sim 4594$ & & & $\mathrm{~L}$ \\
\hline $\mathrm{tRNA}^{\mathrm{Met}}$ & $4775 \sim 4843$ & $4801 \sim 4869$ & $4596 \sim 4664$ & & & $\mathrm{H}$ \\
\hline$N D 2$ & $4844 \sim 5885$ & $4870 \sim 5911$ & $4665 \sim 5706$ & ATC/ATT & T/TAG & $\mathrm{H}$ \\
\hline $\mathrm{tRNA}^{\mathrm{Trp}}$ & $5886 \sim 5954$ & $5912 \sim 5980$ & $5707 \sim 5775$ & & & $\mathrm{H}$ \\
\hline $\mathrm{tRNA}^{\mathrm{Ala}}$ & $5970 \sim 6038$ & $5997 \sim 6065$ & $5792 \sim 5860$ & & & $\mathrm{~L}$ \\
\hline $\mathrm{tRNA}^{\mathrm{Asn}}$ & $6040 \sim 6112$ & $6067 \sim 6139$ & $5862 \sim 5934$ & & & $\mathrm{~L}$ \\
\hline $\mathrm{O}_{\mathrm{L}} \mathrm{R}$ & $6113 \sim 6145$ & $6140 \sim 6178$ & $5935 \sim 5966$ & & & $\mathrm{~L}$ \\
\hline $\mathrm{tRNA}^{\mathrm{Cys}}$ & $6146 \sim 6210$ & $6179 \sim 6244$ & $5967 \sim 6032$ & & & $\mathrm{~L}$ \\
\hline $\mathrm{tRNA}^{\mathrm{Tyr}}$ & $6211 \sim 6278$ & $6238 \sim 6303$ & $6033 \sim 6097$ & & & $\mathrm{~L}$ \\
\hline $\mathrm{COI}$ & $6280 \sim 7824$ & $6305 \sim 7849$ & $6099 \sim 7643$ & ATG & TAA & $\mathrm{H}$ \\
\hline $\operatorname{tRNA}^{\operatorname{Ser}(\mathrm{UCN})}$ & $7822 \sim 7890$ & $7847 \sim 7915$ & $7641 \sim 7709$ & & & $\mathrm{~L}$ \\
\hline $\mathrm{tRNA}^{\mathrm{Asp}}$ & $7897 \sim 7965$ & $7922 \sim 7990$ & $7716 \sim 7784$ & & & $\mathrm{H}$ \\
\hline COII & $7966 \sim 8649$ & $7922 \sim 8674$ & $7785 \sim 8468$ & ATG & TAA & $\mathrm{H}$ \\
\hline $\mathrm{tRNA}^{\mathrm{Lys}}$ & $8653 \sim 8720$ & $8678 \sim 8745$ & $8472 \sim 8539$ & & & $\mathrm{H}$ \\
\hline ATP8 & $8722 \sim 8925$ & $8747 \sim 8950$ & $8541 \sim 8744$ & ATG & TAA & $\mathrm{H}$ \\
\hline ATP6 & $8883 \sim 9563$ & $8908 \sim 9588$ & $8702 \sim 9382$ & ATG & TAA & $\mathrm{H}$ \\
\hline COIII & $9563 \sim 10346$ & $9588 \sim 10371$ & $9361 \sim 10140$ & ATG & T/TAA & $\mathrm{H}$ \\
\hline $\mathrm{tRNA}^{\mathrm{Gly}}$ & $10347 \sim 10415$ & $10372 \sim 10440$ & $10166 \sim 10234$ & & & $\mathrm{H}$ \\
\hline$N D 3$ & $10416 \sim 10762$ & $10441 \sim 10787$ & $10235 \sim 10581$ & ATA & TA & $\mathrm{H}$ \\
\hline $\mathrm{tRNA}^{\mathrm{Arg}}$ & $10763 \sim 10831$ & $10788 \sim 10856$ & $10582 \sim 10650$ & & & $\mathrm{H}$ \\
\hline$N D 4 L$ & $10832 \sim 11128$ & $10857 \sim 11153$ & $10651 \sim 10947$ & ATG & TAA & $\mathrm{H}$ \\
\hline ND4 & $11122 \sim 12499$ & $11147 \sim 12523$ & $10941 \sim 12318$ & ATG & $\mathrm{T}$ & $\mathrm{H}$ \\
\hline tRNA $^{\text {His }}$ & $12500 \sim 12568$ & $12525 \sim 12593$ & $12319 \sim 12387$ & & & $\mathrm{H}$ \\
\hline $\mathrm{tRNA}^{\operatorname{Ser}(\mathrm{AGY})}$ & $12570 \sim 12628$ & $12600 \sim 12657$ & $12388 \sim 12446$ & & & $\mathrm{H}$ \\
\hline $\mathrm{tRNA}^{\mathrm{Leu}(\mathrm{CUN})}$ & $12629 \sim 12698$ & $12653 \sim 12722$ & $12447 \sim 12516$ & & & $\mathrm{H}$ \\
\hline ND5 & $12690 \sim 14519$ & $12723 \sim 14543$ & $12508 \sim 14337$ & ATA & TAA & $\mathrm{H}$ \\
\hline ND6 & $14503 \sim 15030$ & $14527 \sim 15054$ & $14321 \sim 14848$ & ATG & TAA & $\mathrm{L}$ \\
\hline tRNA $^{\text {Glu }}$ & $15031 \sim 15099$ & $15055 \sim 15123$ & $14849 \sim 14917$ & & & $\mathrm{~L}$ \\
\hline Cyt $b$ & $15103 \sim 16242$ & $15127 \sim 16266$ & $14921 \sim 16060$ & ATG & AGA & $\mathrm{H}$ \\
\hline $\mathrm{tRNA}^{\mathrm{Thr}}$ & $16243 \sim 16312$ & $16271 \sim 16340$ & $16061 \sim 16130$ & & & $\mathrm{~L}$ \\
\hline $\mathrm{tRNA}^{\text {Pro }}$ & $16313 \sim 16379$ & $16337 \sim 16403$ & $16131 \sim 16197$ & & & $\mathrm{H}$ \\
\hline D-loop & $16380 \sim 16990$ & $16404 \sim 16964$ & $16198 \sim 16773$ & & & $\mathrm{H}$ \\
\hline
\end{tabular}




\section{4 控制区}

虎、豹和雪豹线粒体控制区位于氨基酸 $\mathrm{tRNA}^{\mathrm{Pro}}$ 和 $\mathrm{tRNA}^{\mathrm{Phe}}$ 之间, 包含启动子、复制和转录调控序列, 无结构基因. Jae-Heup 等人 ${ }^{[54]}$ 将豹属物种的线粒体基 因控制区划分为左域、中间保守区及右域, 且高变区 I (HVS-1)、高变区 II (HVS-2)、重复序列 II (RS-2)、 重复序列 III(RS-3)、保守域 I (CSB-1) 和保守域 II (CSB-2) 分别分布在各域中. 本实验通过与家猫、猎 豹和云豹控制区比较, 确定了虎、豹和雪豹线粒体控 制区各区域的位置. 比较发现, 雪豹的 RS-3 区在长 度上明显小于虎和豹, 而且也比家猫、云豹和猎豹短, 这是雪豹的控制区较短的原因. 但雪豹的控制区与
云豹相当，原因是云豹的 HVS-1 区的长度明显比雪 豹小. 重复序列在控制区内是一种常见的现象, 如 5'-ACAC-ACGTACACACGT-3'序列在豹、虎和雪豹 控制区内分别重复 14,11 和 2 次.

\section{5 tRNA 与 rRNA 基因}

虎、豹、雪豹的线粒体基因组的 $12 \mathrm{~S}$ rRNA 位 于 $\mathrm{tRNA}^{\mathrm{Phe}}$ 和 $\mathrm{tRNA}^{\mathrm{Val}}$ 之间, 全长分别为 950,959 和 $960 \mathrm{bp}$, 与猫和猎豹相比, 有 80,78 和 75 个位点出 现变异, 分别占总位点数的 $8.4 \%, 8.2 \%$ 和 $8.3 \%$, 保 守性较高, $16 \mathrm{~S}$ rRNA 位于 $\mathrm{tRNA}^{\mathrm{Val}}$ 和 $\mathrm{tRNA}^{\mathrm{Leu}(\mathrm{UUR})}$ 之 间，全长分别为 1576,1572 和 $1580 \mathrm{bp}$ ，有 113,114

表 6 虎、豹、雪豹线粒体蛋白质编码基因的碱基使用

\begin{tabular}{|c|c|c|c|c|c|c|c|c|c|c|c|c|}
\hline \multirow{2}{*}{ 基因 } & \multicolumn{4}{|c|}{ 虎(P. tigris) } & \multicolumn{4}{|c|}{ 豹 $(P$. pardus $)$} & \multicolumn{4}{|c|}{ 雪豹(P. uncia) } \\
\hline & $\mathrm{T}(\%)$ & $\mathrm{C}(\%)$ & $\mathrm{A}(\%)$ & $\mathrm{G}(\%)$ & $\mathrm{T}(\%)$ & $\mathrm{C}(\%)$ & $\mathrm{A}(\%)$ & $\mathrm{G}(\%)$ & $\mathrm{T}(\%)$ & $\mathrm{C}(\%)$ & $\mathrm{A}(\%)$ & $\mathrm{G}(\%)$ \\
\hline ND1 & 27.0 & 30.2 & 30.9 & 11.8 & 26.3 & 31.0 & 30.1 & 12.5 & 25.9 & 31.8 & 29.9 & 12.4 \\
\hline$N D 2$ & 25.0 & 29.2 & 35.7 & 9.9 & 24.6 & 29.6 & 35.9 & 9.9 & 25.2 & 29.1 & 36.4 & 9.3 \\
\hline ND3 & 25.9 & 31.2 & 30.5 & 12.4 & 28.8 & 28.2 & 30.3 & 12.7 & 27.2 & 29.8 & 31.2 & 11.8 \\
\hline$N D 4 L$ & 30.9 & 25.9 & 28.6 & 14.5 & 31.4 & 25.2 & 30.9 & 12.5 & 31.1 & 24.5 & 29.3 & 14.1 \\
\hline ND4 & 27.5 & 28.9 & 31.5 & 12.1 & 27.2 & 29.2 & 31.3 & 12.3 & 27.5 & 28.7 & 31.3 & 12.5 \\
\hline ND5 & 27.8 & 28.7 & 31.0 & 12.5 & 28.5 & 28.4 & 31.2 & 11.9 & 28.0 & 28.5 & 31.4 & 12.1 \\
\hline ND6 & 20.6 & 29.5 & 38.1 & 11.7 & 21.8 & 28.4 & 39.0 & 10.8 & 20.3 & 29.7 & 40.0 & 10.0 \\
\hline $\mathrm{COI}$ & 31.0 & 23.9 & 26.0 & 19.1 & 31.7 & 23.2 & 26.7 & 18.4 & 32.1 & 22.9 & 26.0 & 19.0 \\
\hline COII & 27.5 & 25.9 & 30.6 & 16.0 & 26.9 & 26.8 & 31.1 & 15.2 & 27.2 & 26.3 & 31.9 & 14.6 \\
\hline COIII & 28.2 & 28.4 & 26.8 & 16.6 & 28.9 & 28.2 & 26.7 & 16.2 & 28.1 & 28.0 & 28.5 & 15.4 \\
\hline ATP8 & 26.5 & 25.5 & 38.7 & 9.3 & 27.5 & 25.0 & 41.2 & 5.9 & 27.5 & 25.5 & 38.7 & 8.3 \\
\hline$A T P 6$ & 30.4 & 28.0 & 29.0 & 12.6 & 30.2 & 28.0 & 28.0 & 13.8 & 29.2 & 28.8 & 29.5 & 12.5 \\
\hline Cyt b & 27.4 & 30.3 & 27.9 & 14.5 & 27.8 & 30.0 & 27.4 & 14.8 & 26.7 & 23.5 & 27.8 & 14.5 \\
\hline 平均 & 27.4 & 28.1 & 30.9 & 13.3 & 27.8 & 26.0 & 31.5 & 11.4 & 27.4 & 27.5 & 28.7 & 14.0 \\
\hline
\end{tabular}

表 7 虎、豹、雪豹的线粒体 13 个蛋白编码基因密码子的碱基使用

\begin{tabular}{|c|c|c|c|c|c|c|c|c|c|}
\hline \multirow[b]{2}{*}{ 基因 } & \multicolumn{3}{|c|}{ 虎(P.tigris) } & \multicolumn{3}{|c|}{ 豹 (P.pardus $)$} & \multicolumn{3}{|c|}{ 雪豹 $(P$. uncia $)$} \\
\hline & $\begin{array}{c}\text { 第一密码子 } \\
(\mathrm{A}+\mathrm{T})(\%) \\
\end{array}$ & $\begin{array}{c}\text { 第二密码子 } \\
(\mathrm{A}+\mathrm{T})(\%)\end{array}$ & $\begin{array}{c}\text { 第三密码子 } \\
(\mathrm{A}+\mathrm{T})(\%)\end{array}$ & $\begin{array}{r}\text { 第一密码子 } \\
(\mathrm{A}+\mathrm{T})(\%) \\
\end{array}$ & $\begin{array}{r}\text { 第二密码子 } \\
(\mathrm{A}+\mathrm{T})(\%)\end{array}$ & $\begin{array}{r}\text { 第三密码子 } \\
(\mathrm{A}+\mathrm{T})(\%) \\
\end{array}$ & $\begin{array}{r}\text { 第一密码子 } \\
(\mathrm{A}+\mathrm{T})(\%) \\
\end{array}$ & $\begin{array}{r}\text { 第二密码子 } \\
(\mathrm{A}+\mathrm{T})(\%)\end{array}$ & $\begin{array}{r}\text { 第三密码子 } \\
(\mathrm{A}+\mathrm{T})(\%)\end{array}$ \\
\hline$N D 1$ & 50.78 & 57.99 & 61.75 & 50.67 & 57.96 & 61.77 & 50.74 & 57.94 & 61.77 \\
\hline ND 2 & 63.68 & 61.67 & 59.36 & 63.35 & 61.68 & 59.38 & 63.67 & 61.68 & 59.38 \\
\hline ND 3 & 47.82 & 60.00 & 60.00 & 47.65 & 60.01 & 60.08 & 47.84 & 60.06 & 60.02 \\
\hline$N D L$ & 54.54 & 69.69 & 54.54 & 54.54 & 69.68 & 54.52 & 54.56 & 69.69 & 54.52 \\
\hline$N D 4$ & 53.14 & 60.00 & 61.44 & 53.21 & 60.02 & 61.44 & 53.17 & 60.10 & 61.42 \\
\hline ND 5 & 57.86 & 62.45 & 54.91 & 57.84 & 62.46 & 54.90 & 57.88 & 62.47 & 54.94 \\
\hline$N D 6$ & 61.36 & 57.38 & 53.41 & 61.42 & 57.36 & 53.40 & 61.32 & 57.39 & 53.42 \\
\hline COI & 49.71 & 58.44 & 61.75 & 49.82 & 58.45 & 61.73 & 49.73 & 58.42 & 61.77 \\
\hline CO II & 50.43 & 64.04 & 58.33 & 50.54 & 60.06 & 58.34 & 50.44 & 64.08 & 58.35 \\
\hline COIII & 51.72 & 57.09 & 54.79 & 51.68 & 57.10 & 54.72 & 51.76 & 57.07 & 54.78 \\
\hline ATP 8 & 63.24 & 60.29 & 72.06 & 63.21 & 60.30 & 72.06 & 63.23 & 60.28 & 72.08 \\
\hline ATP6 & 50.66 & 62.11 & 64.32 & 50.61 & 62.13 & 64.36 & 50.68 & 62.16 & 64.34 \\
\hline$C y t b$ & 52.37 & 60.53 & 52.37 & 52.32 & 60.52 & 52.37 & 52.38 & 60.56 & 52.38 \\
\hline 平均 & 54.41 & 60.89 & 59.17 & 54.52 & 60.59 & 59.16 & 54.42 & 60.92 & 59.16 \\
\hline
\end{tabular}


和 115 个位点出现变异, 分别占总位点数的 $7.1 \%$, $7.2 \%$ 和 $7.2 \%$, 保守性比 $12 \mathrm{~S}$ rRNA 更高. 虎、豹、雪 豹的线粒体基因组中分别有 22 个 tRNA 基因, 其中 包括 2 个 $\mathrm{tRNA}^{\mathrm{Leu}}$ : tRNA ${ }^{\mathrm{Leu}(\mathrm{UUR})}, \mathrm{tRNA}^{\mathrm{Leu}(\mathrm{CUN})}$ 和 2 个 tRNA $^{\text {Ser. }}$ : tRNA ${ }^{\operatorname{Ser}(U C N)}$, tRNA $^{\text {Ser(AGY) }}$.

\section{6 系统发育关系}

（1）基于 5 个蛋白编码基因组合的系统分析. 基于 5 个蛋白编码基因组合所获得的 MP, ML及贝叶 斯树见图 2(A). 3 种系统分析方法构建的系统树拓扑 结构基本相同, 10 种猫科动物分为两群, 第一群由 虎、豹、狮、美洲豹、雪豹和云豹 6 个物种组成, 云 豹位于分支的最基部; 第二群由豹属中的 3 个物种和 家猫组成. 由构建的拓扑树可见, 单一的豹属系群由 虎、豹、狮、美洲豹、雪豹和云豹组成; 狮和雪豹以 较高的自展值和贝叶斯近似值聚为(狮、雪豹)姊妹物 种; 豹以较低的自展值和贝叶斯近似值聚为(狮、雪豹) 姊妹群, 在 MP, ML 和贝叶斯树节点处的自展值分别 为 42\%, 65\% 和 0.78 , 它们一起构成美洲豹的姊妹群, 但只有中等置信度支持, 在 MP, ML 和贝叶斯树节点 处的自展值分别为 $87 \%, 72 \%$ 和 1.00 ; 虎在系统发生 树中位置较为明确, 靠近分支的基部, 在云豹之后发 生分化; 云豹在 3 个系统发生树中始终位于分支的最 基部, 云豹被并归于豹属有很高的置信度支持, 但暗 示相比其他 5 个物种, 其发生分化较早.

（2）基于 7 个线粒体基因组合的系统分析. 基 于 7 个线粒体基因组合所获得的 MP, ML及贝叶斯 树(图 2(B)). 比较各系统树的拓扑结构可见, MP, ML 和贝叶斯树在各物种的聚类关系上一致. 虎、豹、 狮、美洲豹、雪豹和云豹 6 个物种聚为一支; 家猫、 猎豹、猞猁和美洲狮聚为一支. 云豹仍处在各系统树 分支的最基部, 在 MP, ML 节点处的自检举值和贝叶 斯树节点处的近似值分别为 $95 \%, 88 \%$ 和 0.89 , 具有 较高的支持; 狮和雪豹仍以较高的自展值和贝叶斯 近似值聚为姊妹物种, 在 MP, ML 和贝叶斯树节点处 的自展值和近似值分别为 $98 \%, 92 \%$ 和 0.98 ; 豹构成 (狮、雪豹)这一分支的姊妹群, 在 MP, ML 和贝叶斯 树节点处的自展值分别为 55\%, 58\%和 0.57 , 在节点 处没有得到高自展值的支持. 美洲豹作为豹(狮、雪) 这一分支的姊妹群, 在 MP, ML 树节点处的自展值分 别为 $71 \%$ 和 $78 \%$ 和 0.94 , 在节点处得到中度的自展值 支持; 虎与美洲豹(豹(狮、雪豹) 4 个物种构成姊妹群
关系, 在 MP, ML 节点处的自检举值和贝叶斯树节点 处的近似值分别为 $98 \%, 95 \%$ 和 0.91 , 得到高自展值 的支持.

（3）基于线粒体全序列的系统分析. 基于所能 得到的 7 种猫科动物的线粒体基因组全序列以及另 外 14 种脊椎动物的线粒体全基因组序列, 分别采用 最大似然法及贝叶斯分析法构建了系统发生关系树, 结果产生了统一的拓扑树(图 2(C)). 6 个猫科物种分 为 2 支, 一支包括云豹、豹、虎和雪豹; 另一支由家 猫和猎豹组成. 在前一分支中，云豹处于分支的基部; 虎与豹和雪豹构成姊妹群关系; 豹与雪豹构成姊妹 物种; 各分支节点处的自展值和贝叶斯近似值都为 $100 \%$ 和 1.00. 但是，在整个分析过程中，由于没有狮 和美洲豹的线粒体基因组全序列数据, 因而豹属物 种的系统关系在此分析中不能得到精确地确定.

\section{7 分歧时间的估计}

豹属及属内物种的分歧时间主要依据枝长估 算(表 8). 因为在不同类群中 DNA 序列的进化速率 异质性，对于分歧时间只是粗略地估计. 化石证据 和分子证据已确定, 猫科与大科分歧时间大约在 55 MYA，马科和犀科分歧时间大约在 $(55 \pm 1.5)$ MYA, 这一时间与化石记录允许的时间误差一致, 这里利 用这两个时间作为估算分歧时间的校正点，根据 Janke 和 Arnason ${ }^{[39]}$ 的估算方法对豹属及属内物种的 分歧时间进行粗略估算. 同时, 在基于前述 4 个分

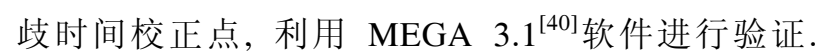
豹属及属内物种的分歧时间估算公式: 豹属物种的 支长 $\times$ 分歧校正点 $(\mathrm{MYA}) /($ 豹属物种的支长+内支 长). 结果可见, 豹属在大约 $11.3 \mathrm{MYA}$ 从猫科中分 出, 形成独立的一支; 约在 $8.66 \mathrm{MYA}$ 属内的物种 开始发生分歧, 首先是云豹与其他物种分离, 粗略 的时间范围 9.3 MYA 5.2 MYA; 随后, 虎约在 6.55 MYA, 粗略的时间范围 6.8 MYA 2.6 MYA; 雪豹约 在 4.63 MYA, 粗略的时间范围 4.8 MYA 1.2 MYA; 豹约在 4.35 MYA, 粗略的时间范围 4.6 MYA 1.82 MYA 相继分歧出去. 值得注意的是, 青藏高原的独 特物种雪豹，其分歧事件、辐射演化和物种种化过 程在时间上与发生在青藏高原的地质事件呈现一 定的相关性, 即与晚新生代青藏高原在 $8,3.6,2.5$ 和 $1.7 \mathrm{MYA}$ 发生的地质构造事件及气候重大转型 时期基本吻合. 

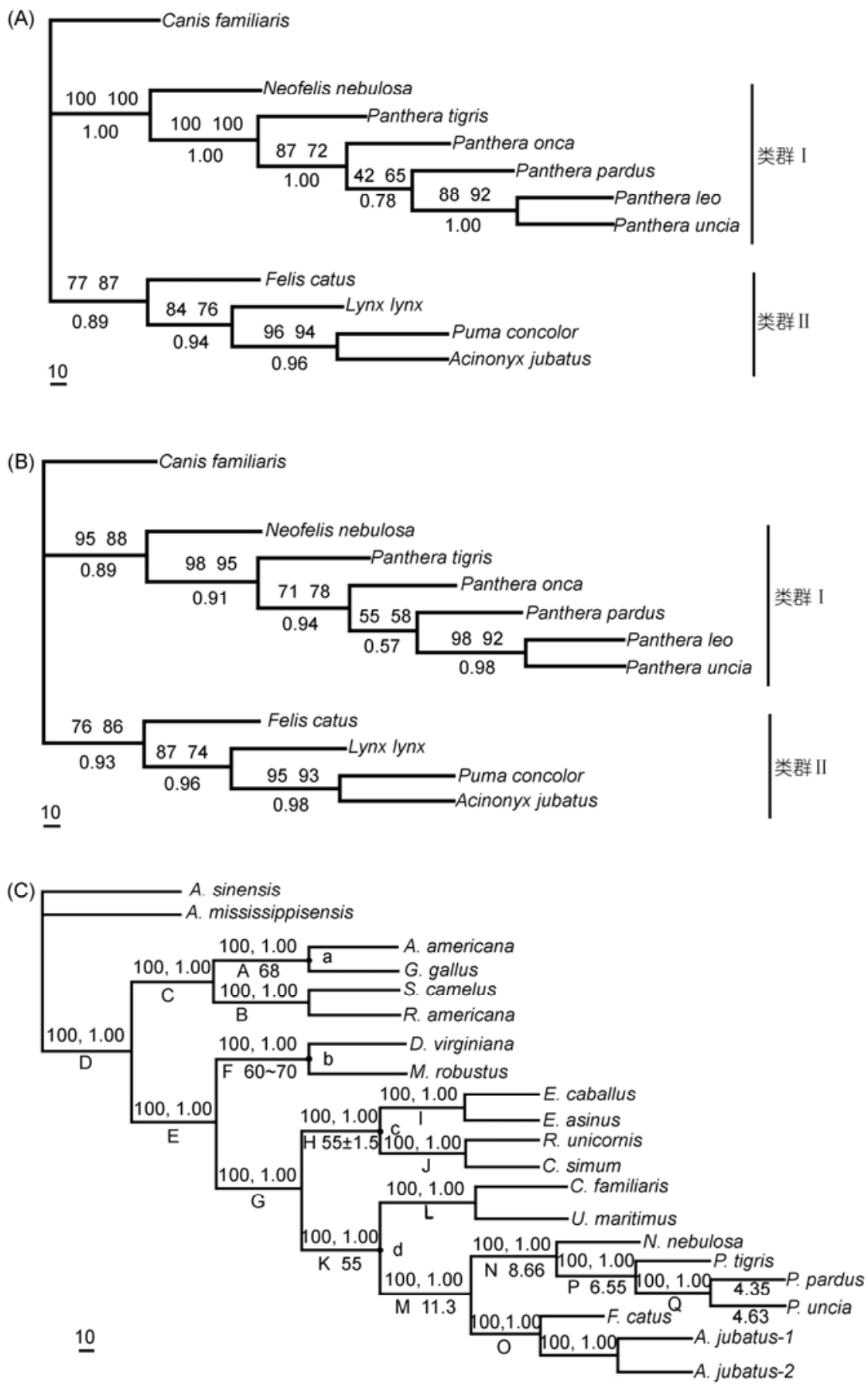

图 2 基于合并序列和全序列构建的分子系统树

（A）基于 5 个线粒体蛋白质编码基因合并序列构建的 MP, ML 和贝叶斯树. 分支上方数字代表置信度, 分支下方数字为贝叶斯近似值; (B) 基 于 7 个线粒体基因合并序列构建的 MP, ML 和贝叶斯树. 分支上方数字代表置信度, 分支下方数字为贝叶斯近似值; (C) 基于 21 种脊椎动物 线粒体去除 ND6 和控制区序列构建的 ML 和贝叶斯统一拓扑树. ML 树的外枝长和内枝长(A Q) 见表 8; 分歧时间根据 ML 树枝长和 4 个分 歧时间校正点估计: a: 鸭科和雉科(Anatidae 和 Phasianidae, $68 \mathrm{MYA})^{[35]}$; b: 负鼠(D. virginiana)和大袋鼠(M. robustusm)(70 MYA 60 MYA ${ }^{[36]}$; c: 马科和犀科(Equidae and Rhinocerotidae $(55 \pm 1.5) \mathrm{MYA})^{[37]}$; d: 猫科和犬科(Felidae 和 Canids, $\left.55 \mathrm{MYA}\right)^{[37]}$. 分支上方数字分别代表 ML 树的 置信度和贝叶斯近似值，下方数字代表分歧时间 
表 8 基于线粒体全序列的最大似然树(ML 树)枝长 ${ }^{\text {a) }}$

\begin{tabular}{|c|c|c|c|c|c|}
\hline 外枝 & 长度 & 标准误 & 内枝 & 长度 & 标准误 \\
\hline A. americana & 0.11411 & 0.00339 & A & 0.03384 & 0.00293 \\
\hline G. gallus & 0.11442 & 0.00341 & B & 0.03521 & 0.00239 \\
\hline S. camelus & 0.10153 & 0.00318 & $\mathrm{C}$ & 0.11582 & 0.00428 \\
\hline R. americana & 0.09381 & 0.00307 & D & 0.09237 & 0.00344 \\
\hline D. virginiana & 0.14865 & 0.00413 & E & 0.22038 & 0.00565 \\
\hline M. robustus & 0.11490 & 0.00374 & F & 0.09510 & 0.00378 \\
\hline E. caballu & 0.03373 & 0.00178 & G & 0.12144 & 0.00441 \\
\hline E. asinus & 0.03821 & 0.00187 & $\mathrm{H}$ & 0.03688 & 0.00229 \\
\hline R. unicornis & 0.06028 & 0.00238 & I & 0.06418 & 0.00257 \\
\hline C. simum & 0.05701 & 0.00231 & $\mathrm{~J}$ & 0.04222 & 0.00218 \\
\hline C. familiaris & 0.11648 & 0.00344 & K & 0.08233 & 0.00356 \\
\hline U. maritimus & 0.12463 & 0.00353 & $\mathrm{~L}$ & 0.03632 & 0.00228 \\
\hline A. jubatus & 0.05731 & 0.00223 & M & 0.06636 & 0.00229 \\
\hline F. cats & 0.04916 & 0.00208 & $\mathrm{~N}$ & 0.01944 & 0.00156 \\
\hline P. pardus & 0.03525 & 0.00174 & $\mathrm{O}$ & 0.01781 & 0.00149 \\
\hline P. uncia & 0.04312 & 0.00189 & $\mathrm{P}$ & 0.01731 & 0.00146 \\
\hline P. tigris & 0.04907 & 0.00206 & Q & 0.01611 & 0.00129 \\
\hline N. nebulosa & 0.06168 & 0.00229 & & & \\
\hline A. mississippiensis & 0.10641 & 0.00358 & & & \\
\hline A. sinensis & 0.09238 & 0.00346 & & & \\
\hline
\end{tabular}

a) ML 树枝长和标准误根据图 2(C)计算得出, ML 树基于 21 种脊椎动物线粒体去除 ND6 和控制区序列构建

\section{3 讨论}

\section{1 豹属线粒体基因组特征}

同其他哺乳动物一样, 在虎、豹和雪豹的线粒体 基因组的 4 种碱基, $\mathrm{G}$ 的含量最低, $\mathrm{A}$ 的含量最高, 3 个 物种碱基的组成表现为 $\mathrm{A}, \mathrm{T}$ 丰富. 实际上, 脊椎动物 线粒体碱基都呈现明显的 AT 偏斜, 尤其是控制区 ${ }^{[54]}$. 家猫、猎豹和云豹也是如此.

除 ND2 基因以 ATC 为起始密码子, ND3 和 ND5 以 ATA 为起始密码子外, 其余蛋白质编码基因都是以 ATG(Met)为起始密码子, 这与大部分脊椎动物线粒体 蛋白编码基因的初始密码子一致.

另外, 3 物种 $C y t b$ 基因的终止密码子都为 AGA, 与其他蛋白质编码基因通常使用的终止密码子明显 不同. 这一现象也出现在大多数哺乳动物的线粒体 基因组中, 如犬 ${ }^{[42] 、}$ 兔 ${ }^{[5]}$ 等. 但在其他类群的线粒体 基因组中, 如两栖类 ${ }^{[56]}$ 、爬行类 ${ }^{[57]}$ 及鸟类 ${ }^{[58]}, C y t b$ 基 因往往缺失终止密码子或以 T/TA/TAA 终止. 由此看 来, 哺乳动物线粒体 $C y t b$ 基因的终止密码子倾向使 用 AGA, 明显有别于其他类群, 而其他蛋白质编码 基因的起始或终止密码子在不同类群间往往没有明 显差异.
脊椎动物 tRNA 基因的长度大约在 59 75 bp 之 间 ${ }^{[19,20]}$. 在 3 物种线粒体基因组中, tRNA 长度最小者 为豹的 $\mathrm{tRNA}{ }^{\mathrm{Ser}(\mathrm{AGY})}(58 \mathrm{bp})$, 最长者为豹的 $\mathrm{tRNA}^{\mathrm{Asn}}(77$ bp). 构建的 tRNA 二级结构显示, 除 tRNA $^{\operatorname{Ser}(\mathrm{AGY})}$ 与 其他脊椎动物一样为二叶草结构, 缺失了“DHU”臂 以外, 其余均为典型的三叶草结构 ${ }^{[59]}$, 这与大多数哺 乳动物的 tRNA 结构相类似.

\section{2 云豹的分类地位}

传统上认为, 豹属由虎、豹、狮、美洲豹和雪豹 组成, 不包含云豹. Johnson 和 $\mathrm{O}^{\prime} \mathrm{Brie}^{[15]}$ 用线粒体 $16 \mathrm{~S}$ rRNA 和 ND5 基因部分序列构建的分子系统树显 示, 云豹与传统的 5 个豹属物种聚为单系, 结果支持 云豹并归于豹属. Bininda-Emonds 等人 ${ }^{[60]}$ 基于形态和 分子数据获得相同的结果. Janczewski 等人 ${ }^{[18]}$ 基于线 粒体 12S rRNA 和 Cyt $b$ 基因部分序列分析认为, 云 豹与虎构成姊妹群关系. 基于两个核基因分析, $\mathrm{Yu}$ 等 人 $^{[61]}$ 却认为云豹应并归于豹属, 它与狮(豹, 雪豹)构 成姊妹群关系. 以犬作为外群, 本文采用 MP, ML 和 贝叶斯方法对两组线粒体整合序列和全序列进行分 析, 并得到较为统一的系统发生关系树. 结果显示, 云豹始终与虎、豹、美洲豹、狮和雪豹 5 个物种聚为 
一支, 且处在聚类分支的最基部, 有很强的置信度支 持(图 2). 因此, 本文结果支持将云豹并归于豹属的 观点.

\section{3 豹属系统发生关系}

豹属的系统进化关系一直是研究的热点. 豹属作 为最近进化而来的一个类群 ${ }^{[62,63]}$, 属内一些物种间的

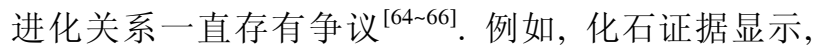
来自东非的最早的豹属化石, 地质年代属于更新世 (2MYA), 形态上类似于虎和狮, 暗示这两个物种具 有较近的亲缘关系. 但是, $\mathrm{Neff}^{[67]}$ 和 Hemmer ${ }^{[68]}$ 认为, 美洲狮(Panthera atrox)的化石(30000 年前)以及欧洲 更新世豹属物种的一个化石 (2 MYA) 具有狮和美洲 豹的特征, 说明狮与美洲豹具有较近的亲缘关系. 基 于形态证据的研究, 其结论也不相同. Pocock ${ }^{[69]}$ 基于 现存物种的形态特征认为, 美洲豹和豹具有较近的 亲缘关系; 雪豹是否并归于豹属仍没有统一意见, 雪 豹因其舌骨基本骨化而无弹性, 此特征与猎豹极其 相似,因而被认为与猎豹的关系较近.

基于两组线粒体基因合并序列, MP, ML 和贝叶 斯 3 种系统分析方法构建的系统树拓扑结构相同(图 2(A)和(B)), 10 种猫科动物分为两群, 第一群由虎、豹、 狮、美洲豹、雪豹和云豹 6 个物种组成, 系统发育关 系为: 云豹(虎(美洲豹(豹(狮、雪豹))), 云豹位于分 支的最基部; 第二群由猞猁、美洲狮、猎豹和家猫组 成. 本研究显示, 云豹应并归豹属, 成为其第 6 个成 员; 虎靠近聚类分支的基部, 与美洲豹、豹、狮和雪 豹为姊妹群关系; 在虎和美洲豹的系统发生关系上, 本研究得出了与 $\mathrm{Yu}$ 和 Zhang ${ }^{[70]}$, Pecon 等人 ${ }^{[71]}$ 基于分 子证据所取得的相一致的结论; 豹与(狮、雪豹)构成 姊妹群关系, 此结论与以前的研究结果不同, 但基于 两组线粒体基因合并序列分析, 豹在系统关系中的 位置没有得到确切的解决, 在支点处的支持较弱; 在 对两组线粒体合并序列分析中, 得出一个新的结果, 即狮和雪豹的姊妹物种关系, 位于聚类分支的最内 部, 且有较高置信度的支持. 在雪豹的系统关系上, 以前的研究得出许多假设. Johnson 和 $\mathrm{O}^{\prime} \mathrm{Brien}^{[15]}$, Mattern 和 McLennan ${ }^{[72]}$ 基于形态学、细胞学以及许多 分子数据分析得出, 雪豹位于豹属系统关系分支的 基部; 最近基于化学信号 ${ }^{[14]}$ 、线粒体控制区序列 ${ }^{[54]}$ 和线粒体与核基因整合数据 ${ }^{[1]}$ 分析又认为, 它与虎具 有最近的亲缘关系. 然而, $\mathrm{Yu}$ 和 Zhang ${ }^{[70]}$ 分析了 6 个
线粒体基因 ( $N D 2, N D 4, N D 5, C y t b, 12 \mathrm{~S}$ 和 $16 \mathrm{~S}$ rRNA) 和 3 个核基因 ( $\beta$-fibrinogen, IRBP 和 TTR)的合并序列 得出, 雪豹与豹构成姊妹物种关系; Buckley-Beason 等人 ${ }^{[73]}$ 基于线粒体 $(A T P 8, C y t b, N D 5$ 和控制区)与核 基因(ATP-7A, BGN, HKl, IDS 和 PLP) 数据分析得出, 雪豹与(豹、美洲虎、虎)构成姊妹群关系. 因此, 本 文得出的狮和雪豹构成姊妹物种关系与以前的研究 结论不同. 总之, 尽管本研究没有完全解决豹属各物 种在系统关系中的确切位置, 但基于线粒体全序列和 线粒体基因合并序列的分析，将有助于豹属进化关系 的探讨并提供新的数据.

\section{4 分歧时间}

此前, 有一些关于豹属物种辐射性演化的分歧 时间探讨的报道，但基于不同的分子数据和不同的 分析方法, 其结果存在一定的差异. 最近研究显示, 在豹属物种间的分歧时间估算上，基于分子数据和 采用古生物学方法所得出的结果不统一 ${ }^{[1,15]}$. 根据目 前古生物学证据显示, 最早的豹属物种的化石来自于 更新世时期的东非和欧洲，距今大约 2 百万年 ${ }^{[67,68]}$. 根据分子和生化数据分析认为, 豹属分歧时间大约

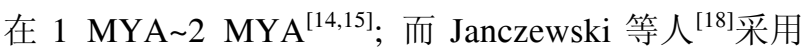
$C y t b$ 基因的部分序列为分子钟进行分析, 推测豹属约 在 3 MYA 从豹亚系中分离出来, 豹属内各物种间的 相互分离大约在 1 MYA 3 MYA; Bininda-Emonds 等人 ${ }^{[60]}$ 基于合并的系统发生信息提出, 豹属各物种 间约在 4.2 MYA 2.1 MYA 发生分歧. 一些科学家认 为, 豹属大约是在至少 5 MYA 从猫科中分化出来 ${ }^{[63]}$. Johnson 等人 ${ }^{[1]}$ 基于化石和分子数据分析认为, 在豹 属内各物种间的分歧事件发生的时间估计上，化石 证据时间比基于常染色体、 $\mathrm{X}, \mathrm{Y}$ 性染色体、线粒体 基因分析结果平均低估了 76\%和 73\%或 79\%.

根据 21 种脊椎动物线粒体基因组全序列构建的 ML 树的支长，并结合 4 个可靠分歧事件校正点，本 文获得了豹属物种粗略的分歧时间：豹属大约在 11.3 MYA 从其他猫科物种分化出来, 分歧事件发生 在地质年代的晚中新世和早上新世; 物种间的分化 发生在 10 MYA 1 MYA. 首先是云豹在 8.66 MYA, 粗略的时间范围 9.3 MYA 5.2 MYA，与豹属的其他 物种发生分歧; 虎在 6.55 MYA，粗略的时间范围 6.8 MYA 2.6 MYA，发生分歧; 雪豹在 4.63 MYA，粗略 的时间范围 4.8 MYA 1.2 MYA，发生分歧; 豹在 
4.35 MYA, 粗略的时间范围 4.6 MYA 1.82 MYA, 发生分歧. 本文估计的豹属物种的分歧时间与一些 分子数据基本一致, 比化石证据略早. 而依据化石证 据, 虎大约在 1.8 MYA 1.6 $\mathrm{MYA}^{[63,68]}$ 发生分歧, 豹 大约在 $1.3 \mathrm{MYA}^{[74]}$. 对豹属物种分歧时间的估算与 先前的研究结果较一致 ${ }^{[1,18,60]}$.

\section{5 雪豹分歧事件和种化过程与青藏高原隆起}

雪豹作为青藏高原的特有物种，其分歧事件的 发生、辐射演化和种形成过程(时间范围 4.6 MYA $1.82 \mathrm{MYA})$ 与青藏高原的构造事件和气候的转型相 一致. 地质学研究表明, 在中国西南, 青藏高原的隆 起是多阶段、非均匀、不等速的过程, 但发生在晚新 生代 8, 3.6, 2.5 和 1.7 MYA 的构造事件和强烈隆起对 高原的隆起有重要意义 ${ }^{[75]}$. 分子估计的雪豹的主要 分支事件、种群扩张和种化过程也发生在这几个时期, 证明了雪豹的起源和演化与青藏高原阶段性隆起导 致的环境变化密切相关. 8 MYA, 是北半球多数地区 气候和环境发生重大转型的时期, 如阿拉伯海上的涌 流增强, 显示印度洋季风出现或增强 ${ }^{[76]}$; 拉萨西北 羊八井地堑断裂活动也发生在 $8 \mathrm{MYA}^{[77]}$, 临夏盆地 在 7.78 MYA 6.25 MYA 开始地层颜色永久性改变 和干旱气候急剧发展 ${ }^{[78]}$, 亚洲内陆气候干旱增加, 印 度和东亚季风开始形成 ${ }^{[79]}$. 这些都表明, 青藏高原 的自然环境在 $8 \mathrm{MYA}$ 有过剧烈的变化, 这时起源于 亚洲的豹属在 11.3 MYA 从猫科中分化出来并进入
其演化历程.

4.5 MYA 以后, 西北高原开始隆起 ${ }^{[80]}, 3.5 \mathrm{MYA}$ 以后, 柴达木盆地进入成盐期, 现代亚洲季风开始出 现 ${ }^{[75,79]}$, 该阶段被称为青藏高原运动 $\mathrm{A}$ 幕 ${ }^{[80]}$. 这一时 期雪豹与豹属的其他物种发生分化(4.63 MYA), 原 始的雪豹可能由于某种特殊或偶然的机会进入尚在 隆起中的青藏高原, 揭开了高原环境中生存竞争的 前幕，这是雪豹演化过程的第一阶段.

在 2.6 MYA，亚洲季风系统稳定建立，高原向更 高的海拔发展, 这一时期是青藏高原隆起的第二阶 段, 被称为青藏高原运动 $\mathrm{B}$ 幕 ${ }^{[75]}$. 随着气候等生态条 件的逐步稳定, 雪豹在长期的生存竞争中从形态、行 为以及生理等方面对高原环境产生了重要的适应, 此时期可能是雪豹演化为高原特有种的重要时期, 为雪豹演化过程的第二阶段.

1.7 MYA 后是雪豹种化的主要时期, 1.7 MYA 后也是气候发生重大转型的时期, 青藏高原已接近 于现今的高度，该时期是青藏高原隆起的第三阶段, 被称为青藏高原运动 $\mathrm{C}$ 幕 ${ }^{[75]}$. 这一时期, 分布于高 原上的雪豹开始向周边地区辐射扩散, 并最终演化 成高原特有物种。雪豹分歧事件与辐射演化过程与 青藏高原地质事件和气候转型在时间上基本吻合, 暗示雪豹种的起源和扩散可能与青藏高原阶段性 隆起所导致的环境变化密切相关, 雪豹种群的分布 格局可能是高原阶段性隆起和气候重大转型的直 接结果.

\section{参考文献}

1 Johnson W E, Eizirik E, Pecon S J, et al. The late radiation of modern Felidae: a genetic assessment. Science, 2006, 311: 73-77

2 Werdelin L. Small pleistocene felines of North America. J Vert Paleo, 1985, 5: 194-210

3 Hunt R M J. Biogeography of the order Carnivora. In: Carnivore Behavior, Ecology, and Evolution. Vol 2. New York: Cornell University Press, 1996. 485-541

4 Werdelin L. Morphological patterns in the skulls of cats. Biol J Linnean Soc, 1983, 19: 375-391

5 Radinsky L B. Evolution of skull shape. Representative modern carnivores. Biol J Linnean Soc, 1981, 15: 369-388

6 Wurster-Hill D H, Centerwall W R. The interrelationships of chromosome banding patterns in Procyonids, Viverrids and Felids. Cytogenet Cell Genet, 1982, 34: 178-192

7 Modi W S, O'Brien S J. Quantitative cladistic analysis of chromosomal banding data among species in three orders of mammals: hominoid primates, felids and arvicolid rodents. In: Chromosome Structure and Function: Impact of New Concepts. New York: Plenum Press, 1988. $215-242$

8 Salles L O. Felid phylogenetics: extant taxa and skull morphology (Felidae, Aeluroidea). American Museum Novitates, 1992, 3047: 1-67

9 Collier G E, O’Brien S J. A molecular phylogeny of the Felidae: immunological distance. Evolution, 1985, 39: 437-487

10 O'Brien S J, Collier G E, Benveniste R E, et al. Setting the molecular clock in Felidae: the great cats Panthera. In: Tilson R L, Seal U S, eds. Tigers of the World: the Biology, Biopolitics, Management and Conservation of an Endangered Species. Park Ridge, NJ: Noyes Publications, 1987. 10-27 
11 Pecon S J, Johnson W E, Goldman D, et al. Phylogenetic reconstruction of South American felids defined by protein electrophoresis. J Mol Evol, 1994, 39: 296-305

12 Benveniste R E. The contributions of retroviruses to the study of mammalian evolution. In: Molecular Evolutionary Genetics. New York: Plenum Press, 1985. 359-417

13 Pecon S J, O'Brien S J. Patterns of Y and X chromosome DNA sequence divergence during the Felidae radiation. Genetics, 1998, 148: $1245-1255$

14 Bininda-Emonds O R. The utility of chemical signals as phylogenetic characters: an example from the felidae. Biol J Linnean Soc, 2001, 72: $1-15$

15 Johnson W E, O’Brien S J. Phylogenetic reconstruction of the Felidae using 16SrRNA and NADH-5 mitochondrial genes. Mol Evol, 1997, 44: $98-116$

16 Saccone C, Lanave C, Pesole G, et al. Influence of base composition on quantitative estimates of gene evolution. Methods Enzymol, 1999, 183: $570-583$

17 Wu X B, Zheng T, Jiang Z G, et al. The mitochondrial genome structure of the clouded leopard (Neofelis nebulosa). Genome, 2007, 50: 252-257

18 Janczewski D N, Modi W S, Stephens J C, et al. Molecular evolution of mitochondrial 12S RNA and cytochrome $b$ sequencse in the Pantherine lineage of Felidae. Mol Biol Evol, 1995, 12: 690-707

19 Lopez J V, Cevario S, O’Brien S J. Complete nucleotide sequences of the Domestic cat (Felis catus) mitochondrial genome and a transposed mtDNA tandem repeat (Numt) in the nuclear genome. Genomics, 1996, 33: 229-246

20 Burger P A, Steinborn R, Walzer C, et al. Analysis of the mitochondrial genome of cheetahs (Acinonyx jubatus) with neurodegenerative disease. Gene, 2004, 338: 111-119

21 Rychlik W, Rychlik P. Oligo Primer Analysis Software. Version 6.01. Molecular Biology Insights, Inc., Cascade, Colorado, 2000

22 Altschul S F, Madden T L, Schäer A A, et al. Gapped BLAST and PSI-BLAST: a new generation of protein database search programs. Nucleic Acids Res, 1997, 25: 3389-3402

23 Thompson J D, Gibson T J, Plewniak F, et al. The clustal X windows interface: xexible strategies for multiple sequence alignment aided by quality analysis tools. Nucleic Acids Res, 1997, 25: 4876-4882

24 Swofford D L. PAUP*: Phylogenetic Analysis Using Parsimony(*and Other Methods), 2003

25 Huelsenbeck J P, Hillis D M. Success of phylogenetic methods in the four-taxon case. Syst Biol, 1993, 42: 247-264

26 Ronquist, Huelsenbeck J P. MrBayes 3: Bayesian phylogenetic inference under mixed models. Bioinformatics, 2003, 19: 1572-1574

27 Posada D, Buckley T R. Model selection and model averaging in phylogenetics: advantages of the AIC and Bayesian approaches over likelihood ratio tests. Syst Biol, 2004, 53: 793-808

28 Rannala B, Yang Z. Probability distribution of molecular evolution trees: a new method of phylogenetic inference. J Mol Evol, 1996, 43: 304-311

29 Leaché A D, Reeder T W. Molecular systematics of the eastern fence lizard (Sceloporus undulatus): a comparison of parsimony, likelihood, and Bayesian approaches. Syst Biol, 2002, 51: 44-68

30 Shimodaira H, Hasegawa M. Multiple comparisons of log-likelihoods with applications to phylogenetic inference. Mol Biol Evol, 1999, 16: $1114-1116$

31 Asakawa S, Kumazawa Y, Araki T, et al. Strand-specific nucleotide composition bias in echinoderm and vertebrate mitochondrial genomes. J Mol Evol, 1991, 32: 511-520

32 Arnason U, Gullberg A, Gretarsdottir S, et al. The mitochondrial genome of the sperm whale and a new molecular reference for estimating eutherian divergence dates. J Mol Evol, 2000, 50: 569-578

33 Hillis D M, Moritz C. An overview of applications of molecular systematics. In: Molecular Systematics. Sunderland: Sinauer Associates, 1990

34 Glazko G V, Nei M. Estimation of divergence times for major lineages of primate species. Mol Biol Evol, 2003, 20: 424-434

35 Waddell P J, Cao Y, Hasegawa M, et al. Assessing the Cretaceous superordinal divergence times within birds and placental mammals by using whole mitochondrial protein sequences and an extended statistical framework. Syst Biol, 1999, 48: 119-137

36 Nilsson A M, Gullberg A, Spencer P, et al. Marsupial relationships and a timeline for marsupial radiation in South Gondwana. Gene, 2004, 340: 189-196

37 Yang Z, Yoder A D. Comparison of likelihood and Bayesian methods for estimating divergence time using multiple gene loci and calibration points, with application to a radiation of cute-looking mouse lemur species. Syst Biol, 2003, 52: 705-716 
38 Huelsenbeck J P, Rannala B. Phylogenetic methods come of age: testing hypotheses in an evolutionary context. Science, 1997, 276: 227-232

39 Janke A, Arnason U. The complete mitochondrial genome of Alligator mississippiensis and the separation between recent archosauria (birds and crocodiles). Mol Biol Evol, 1997, 14: 1266-1272

40 Kumar S, Tamura K, Nei M. MEGA3: integrated software for molecular evolutionary genetics analysis and sequence alignment. Brief Bioinform, 2004, 5: 150-163

41 Xu X, Gullberg A, Arnason U. The complete mitochondrial DNA (mtDNA) of the donkey and mtDNA comparisons among four closely related mammalian species-pairs. J Mol Evol, 1996, 43: 438-446

42 Kim K S, Seong E L, Ho W J, et al. The complete nucleotide sequence of the domestic dog (Canis familiaris) mitochondrial genome. Mol Phylogenet Evol, 1998, 10: 210-220

43 Arnason U, Adegoke J A, Bodin K, et al. Mammalian mitogenomic relationships and the root of the eutherian tree. Proc Natl Acad Sci USA, 2002, 99: 8151-8156

$44 \mathrm{Xu} \mathrm{X}$, Arnason U. The complete mitochondrial DNA sequence of the horse, Equus caballus: extensive heteroplasmy of the control region. Gene, 1994, 148: 357-362

$45 \mathrm{Xu} \mathrm{X}$, Arnason U. The complete mitochondrial DNA sequence of the white rhinoceros, Ceratotherium simum, and comparison with the mtDNA sequence of the Indian rhinoceros, Rhinoceros unicornis. Mol Phylogenet Evol, 1997, 7: 189-194

$46 \mathrm{Xu} \mathrm{X}$, Janke A, Arnason U. The complete mitochondrial DNA sequence of the greater Indian rhinoceros, Rhinoceros unicornis, and the Phylogenetic relationship among Carnivora, Perissodactyla, and Artiodactyla (+ Cetacea). Mol Biol Evol, 1996, 13: 1167-1173

47 Janke A, Feldmaier-Fuchs G, Thomas W K, et al. The marsupial mitochondrial genome and the evolution of placental mammals. Genetics, 1994, 137: 243-256

48 Desjardins P, Morais R. Sequence and gene organization of the chicken mitochondrial genome. A novel gene order in higher vertebrates. J Mol Biol, 1990, 212: 599-634

49 Johnson K P, Sorenson M D. Comparing molecular evolution in two mitochondrial protein coding genes (cytochrome b and ND2) in the dabbling ducks (Tribe: Anatini). Mol Phylogenet Evol, 1998, 10: 82-94

50 Härlid A, Janke A, Árnason Ú. The complete mitochondrial genome of Rhea americana and early avian divergences. J Mol Evol, 1998, 46: 669-679

51 Härlid A, Janke A, Árnason Ú. The mtDNA Sequence of the ostrich and the divergence between paleognathous and neognathous birds. J Mol Evol, 1997, 14: 754-761

52 Janke A, Arnason U. The complete mitochondrial genome of Alligator mississippiensis and the separation between recent Archo-sauria (birds and crocodiles). J Mol Biol Evol, 1997, 14: 1266-1272

53 吴孝兵, 王义权, 周开亚, 等. 杨子䲞的线粒体全基因组与魾类系统发生. 科学通报, 2003, 48: 1954-1958

54 Jae-Heup K, Eizirik E, O'Brien S J, et al. Structure and patterns of sequence variation in the mitochondrial DNA control region of the great cats. Mitochondrion, 2001, 3: 279-292

55 Gissi C, Gullberg A, Arnason U. The Complete mitochondrial DNA sequence of the Rabbit (Oryctolagus cuniculus). Genomics, 1998, 50: $161-169$

56 Sano N, Kurabayashi A, Fujii T, et al. Complete nucleotide sequence and gene rearrangement of the mitochondrial genome of the bell-ring frog, Buergeria buergeri (family Rhacophoridae). Genes Genet Syst, 2004, 79: 151-163

57 Han D M, Zhou K Y. Complete sequence and gene organization of the mitochondrial genome of Tokay (Gekko gecko). Zool Res Apr, 2005, 26: $123-128$

58 孙毅, 马飞, 肖冰, 等. 鸮形目两种鸟类线粒体基因组全序列测定与比较研究. 中国科学 C 辑: 生命科学, 2004, 34: 527-536

59 Frazer-Abel A A, Hagerman P J. Determination of the angle between the acceptor and anticodon stems of a truncated mitochondrial tRNA. J Mol Biol, 1999, 85: 581-593

60 Bininda-Emonds O R, Gittleman J L, Purvis A. Building large trees by combining phylogenetic information: a complete phylogeny of the extant Carnivora (Mammalia). Biol Rev, 1999, 74: 143-175

61 Yu L, Li Q W, Ryder O A, et al. Phylogenetic relationships within mammalian order Carnivora indicated by sequences of two nuclear DNA genes. Mol Phylogenet Evol, 2004, 33: 694-705

62 Kurten B, Anderson E. Pleistocene mammals of North America. New York: Columbia University Pree, 1980

63 Wayne R K, Benveniste R E, Janczewski D N, et al. Molecular and biochemical evolution of the Carnivora. In: Carnivore Behaviour, Ecology and Evolution. London: Chapman and Hall, 1989. 465-494 
64 King V, Goodfellow P N, Pearks W A J, et al. Evolution of the male-determining gene SRY within the cat family Felidae. Genetics, 2007, 175: $1855-1867$

65 O'Brien S J, Johnson W E. The evolution of cats. Genomic paw prints in the DNA of the world's wild cats have clarified the cat family tree and uncovered several remarkable migrations in their past. Sci Am, 2007, 297: 68-75

66 Davis B W, Li G, Murphy W J. Supermatrix and species tree methods resolve phylogenetic relationships within the big cats, Panthera (Carnivora: Felidae). Mol Phylogenet Evol, 2010, 56: 64-76

67 Neff N A. The Big Cats: the Painting of Guy Coheleach. New York: Abrams, 1982

68 Hemmer H. The evolutionary systematics of living Felidae: present status and current problems. Carnivore, 1978, 1: 71-79

69 Pocock R I. Notes upon some African species of the genus Felis, based upon specimens recently exhibited in the society's garden. Proc Zool Soc Lond, 1907: 656-667

70 Yu L, Zhang Y P. Phylogenetic studies of pantherine cats (Felidae) based on multiple genes, with novel application of nuclear $\beta$-fibrinogen intron 7 to carniores. Mol Phyl Evol, 2005, 35: 483-495

71 Pecon S J, Wilkerson A J P, Murphy W J, et al. Phylogenetic Assessment of Introns and SINES within the Y chromosome using the cat family Felidae as a species tree. Mol Biol Evol, 2004, 21: 2299-2309

72 Mattern M Y, McLennan D A. Phylogeny and speciation of Felids. Cladistics, 2000, 16: 232-253

73 Buckley-Beason V A, Johnson W E, Nash W G, et al. Molecular evidence for species-level distinctions in clouded leopards. Curr Biol, 2006, 16: $2371-2376$

74 Turner A. New fossil carnivore remains from the Sterkfontein hominid site (Mammalia: Carnivora). Ann Transvall Mus, 1987, 34: 319-347

75 Li J J, Fang X M, Pan B T. Late Cenozoic intensive uplift of Qinghai-Xijiang Plateau and its impacts on environments in surrounding area. Quaternary Sci (in Chinese), 2001, 21: 381-391

76 Kroon D, Steen T, Troelstra S R. Onset of monsoonal related upwelling in the western Arabian Sea as revealed by planktonic foraminifers. Proc Ocean Drill Program Sci Results, 1991, 117: 257-263

77 Harrison T M, Copeland P, Kidd W S F, et al. Activation of the Nyainqentanghla shear Zone: implications for uplift of the southern Tibetan Plateau. Tectonics, 1995, 14: 658-676

78 方小敏, 李吉均, 朱俊杰, 等. 甘肃临夏分地新生代地层绝对年代测定与划分. 科学通报, 1997, 42: 1457-1471

79 An Z, Kutzbach J E, Prell W L, et al. Evolution of Asian monsoons and phased uplift of the Qinghai-Tibetan Plateau since late Miocene times. Nature, 2001, 411: 62-66

80 Zheng H, Powell C M, An Z, et al. Pliocene uplift of the northern Tibet plateau. Geology, 2000, 28: 715-718 